\title{
Employment Satisfaction and Maslow's Hierarchy of Needs Expansion Theory by the Pastoral Care Department
}

\author{
Mariola Stawasz \\ Pastoral Care Department, Fu Jen Catholic University Hospital, No. 69, Guizi Rd., Taishan Dist., New Taipei City 24352, Taiwan \\ (R.O.C.)

\begin{abstract}
The author decided to explore Maslow’s theory of needs within a Catholic hospital in which 80\% of the medical and service staff are non-Christians. The requirements to be focused on include a vision of medical care and service in accordance with the values and mission of Catholicism, and in the context of the highest level of attachment of employees to Cardinal Tien Hospital. The author also wondered whether there was evidence of a shift in employee needs for a sense of meaning in the workplace. If so, how should, or could, the organization and its leaders respond to it?
\end{abstract}

Key words: Catholic hospitals, pastoral care, job satisfaction, Maslow theory, commitment, self-transcendent.

\section{Introduction}

In Taiwan, there are ten Catholic hospitals in which approximately $80 \%$ of the workers are non-Christians, but they must face and partake of the Church's vision of a Catholic Hospital and its mission. This study investigates, with the help of Abraham Maslow's need hierarchy and theory of motivation, the type and degree of satisfaction among staff members today at Cardinal Tien Hospital (CTH) [1]. At CTH, the Pastoral Care Department (PCD) helps employees as a support system to deal with various difficulties in their work.

However, if the hospital wants to succeed in any facet, it must increase satisfaction among its employees. We can always trace this phenomenon of appreciation to the motivation of employees. From productivity and profitability to recruiting and retention, hardworking, and happy employees lead to triumph [2]. Motivation is a sign of fidelity for healthcare employees who are satisfied with their work and contributes much to the efforts healthcare organizations make to deliver

Corresponding author: Sr. Mariola Zofia Stawasz, SSpS, D. Min, research fields: pastoral care and spirituality. high-quality, patient/resident-centered care. Once staff members are happy in their works, a positive effect on the quality of care is being provided results: "happy employees = happy patients and happy residence” [3].

I believe that with clearly defined and measurable goals, employees know what is expected of them and how they are evaluated, which is a different concern in itself than the single question of “success". According to Christina Shalley in the Academy of Management Journal: “Managers Can Not Constantly Drive Motivation, or Keep Track of an Employee's Work Continuously" [4], goals are, therefore, an essential tool for managers, since targets can function as a self-regulatory mechanism that helps employees prioritize tasks.

Leaders of CTH try to exploit goals and keep employees on track, which improves their performance. Improving employee performance means improving employee satisfaction, and attempting to reach the highest point of transcendence, which at CTH is the witness of Catholic values in the practice of medicine. That is what the author emphasizes in the paper.

\section{Materials and Methods}


The main goal of this research was to examine the level of employee satisfaction at CTH according to the Maslow theory and to explore possibilities on how to reach the highest level of satisfaction among personnel who serve in Catholic medical institutions. Equally important to our goals was to study how to develop the reputation and make better known the special characteristics of the hospital in the medical world of Taiwan.

\subsection{Description and Explanation of the Questionnaire}

In year 2016 from September 1th to 30th a total of 1,437 questionnaires were distributed to physicians ( $t$ = 239), nurses $(t=440)$, technicians $(t=251)$, nurse assistants $(t=120)$, specialist nurses $(t=69)$, and members of the administrative staff $(t=318)$ at CTH. As many as 786 surveys were returned, which amounted to a valid response rate of $53.58 \%$. The nurses had the highest review responses, with $74.77 \%$, with the specific percentages among groups as follows: specialist nurses 33.33\%, nurse assistants 60\%, members of the administrative staff $53.14 \%$, technicians $35.25 \%$. The lowest rate of responses was from physicians-26.36\% (Table 1).

The questionnaire involved questions on a number of topics, including working environment and safety, salary and benefits, promotion system, education and training, decision-making and leadership, and hospital identity. The survey questionnaires asked a total of 40 questions with the Likert type responses based on a rating scale of 5 signifying "very satisfied", 4 "satisfied", 3 "neutral", 2 "dissatisfied", and 1 "very dissatisfied".

This research also included the photographic record $(t=780)$ of employees who received counseling from the CTH's PCD during the period from August 1st to December 30th in the year 2016 (Table 2).

\section{Results}

The result of the questionnaires was analyzed using SWOT diagrams. SWOT stands for strengths, weaknesses, opportunities, and threats. Strengths and weaknesses are internal factors, and opportunities and threats are external factors [5]. In this way, we tried to decide whether to embark on a specific project or strategy on the basis of perceived pros and cons.

The outcome of the sample survey shows that employees of the CTH have a strong ability to manage and lead the hospital (73.18\%). A variety of opportunities to grow in professional training and possibilities for personal development as well appeared to be well established (69.59\%). Besides, employees seem to sense empowerment in the vision and mission of the hospital (66.92\%). Employees were not satisfied, however, with the salary and welfare situations (66.69\%), and felt a lack of personal confidence (68.24\%) (Table 3).

The survey shows that CTH workers are hardworking personally and profoundly conscious of the importance of their work. At the same time, however, employees at the hospital are aware of personal limitations, which may lead to various forms of weakness (Table 4).

To grasp more results of the SWOT examination above, two of the SWOT tables were integrated and analyzed again in Fig. 1.

Table 1 Employees responding to the questionnaires.

\begin{tabular}{lll}
\hline Position & Number & Valid responses \% \\
\hline Physicians & 239 & $26.36 \%$ \\
Nurses & 440 & $74.77 \%$ \\
Technicians & 251 & $35.25 \%$ \\
Nurse assistants & 120 & $60 \%$ \\
Specialist nurse & 69 & $33.33 \%$ \\
Administrative staff & 318 & $53.14 \%$ \\
\hline
\end{tabular}

Table 2 CTH's employees who received counseling from the pastoral care department.

\begin{tabular}{ll}
\hline Item & Numbers of the employees \\
\hline Pastoral care workers & 469 \\
approached & 50 \\
Supervisor/peer referrals & 261 \\
Employees asking for help & 780 \\
Total &
\end{tabular}


Table 3 SWOT analysis of the questionnaires of employee satisfaction.

\begin{tabular}{ll}
\hline S-Strength (internal, positive) & W-Weakness (internal, negative) \\
$\begin{array}{ll}\text { (1) Strong ability to manage and to lead the hospital (73.18\%) } \\
\text { (2) Opportunity for professional development, training, and }\end{array}$ & $\begin{array}{l}\text { (1) Not satisfied with the salary and welfare (66.69\%) } \\
\text { growth (69.59\%) }\end{array}$ \\
$\begin{array}{ll}\text { (3) Empock of personal confidence (68.24\%) } \\
\text { (3) Communication difficulties among departments (66.21\%) }\end{array}$ \\
\hline O-Opportunity (external affirmative) & T-Threats (external, harmful) \\
\hline $\begin{array}{l}\text { (1) Healthy CTH community system, many Church spiritual } \\
\text { resources (89.45\%) }\end{array}$ & $\begin{array}{l}\text { (1) Assimilation with (salary, equipment, welfare, indifference) } \\
\text { (67.10\%) }\end{array}$ \\
$\begin{array}{ll}\text { (2) Commitment to the mission of the hospital (89.40\%) } \\
\text { (3) Care for the poor and persons in special needs (89.00\%) }\end{array}$ & $\begin{array}{l}\text { (67.01\%) } \\
\text { (3) Difficulties in expressing the fruits of the work (66.54\%) }\end{array}$ \\
\hline
\end{tabular}

Table 4 SWOT analysis form staff records taken by pastoral care workers.

S-Strength (internal, positive)

(1) Hardworking (85\%)

(2) The qualities of warm care (75\%)

(3) High recognition of the hospital (83\%)
W-Weakness (internal, negative)

(1) Care for self and habits of over-consumption (65\%)

(2) Employees with exceptional potential have an excellent opportunity to leave for better opportunities (15\%)

(3) Interpersonal communication difficulties (15\%)

O-Opportunity (external affirmative) T-Threats (external, harmful)

(1) Family interaction between workers and care (experiencing the (1) Stressful work and difficulties to deal with (55\%) human touch) (75\%)

(2) Good servant leadership models (65\%)

(3) Friendly environment (77\%)

(2) The dilemma of Taiwan's medical

environment/competitiveness (55\%)

(3) Threats of material culture and “money business" (44\%)

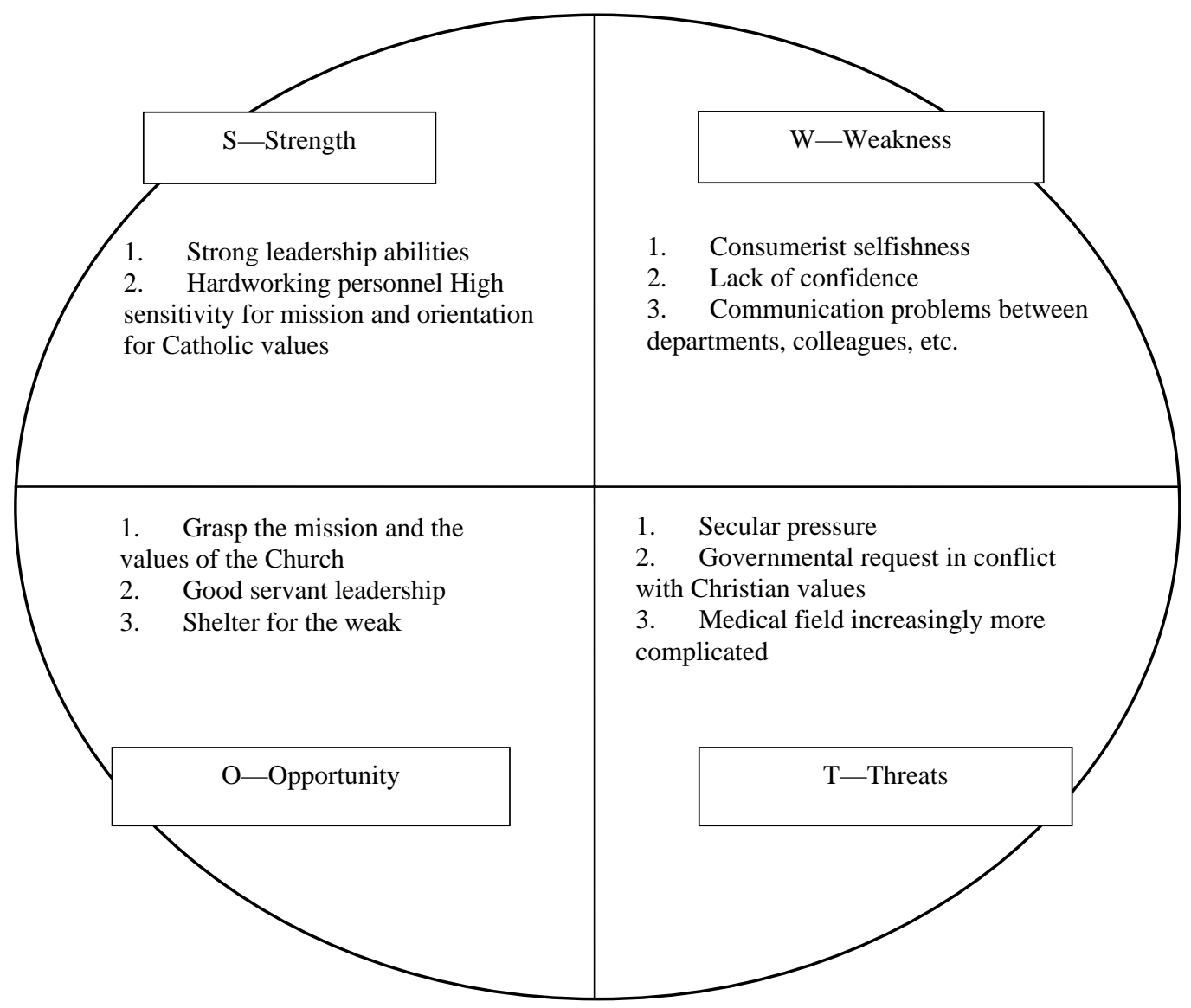

Fig. 1 SWOT analysis table integrated from the above two tables. 


\section{Discussion}

Abraham Maslow proposed that people have five basic levels of needs, which range from lower-level "biogenic" to higher-level "psychogenic" needs. More specifically, these needs can be thought of as physiological [6] (food and clothing, for example); safety (order, stability, routine, control, health, for example); social (love, affection, belonging, for example); esteem (self-acceptance, success, independence, prestige, reputation, status, for example); and self-actualization, or reaching one's full potential. Maslow's thoughts are classically debated in terms of perspectives for the buyer and employee motivation.

Given the above definition of needs, marketers know that needs can be learned through conditioning, which can help marketers "lead" consumers to engage in such behaviors as "responding more positively to advertisements, developing positive attitudes toward brands, purchasing more in grocery stores and restaurants, and purchasing more with credit cards" [7].

In my understanding, looking at Maslow's theory through the results available in responses to the questionnaires, Maslow offers us "cheap grace”. To Maslow, "salvation is a by-product of self-actualizing work and self-actualizing duty"; salvation comes from "hard work and total commitment to doing well the job that fate or personal duty calls you to do, or any important job that 'calls for' doing” [8]. In other words, Maslow's ideas presuppose self-actualization without God.

As a professional "motivator" for personnel at the hospital, the author asks how she can better assist each of our workers to be committed and at least compliant, but not non-committal. Through the research of this current study, we can observe that a high percentage of CTH employees have strengths and opportunities for obedience (a compliant team member says, "I can do it if I am told to") and sense an empowerment to move toward total commitment (a truly committed team member passionately says, “I will do it!”) (Fig. 2) [10].

For this achievement, leaders and pastoral care workers at $\mathrm{CTH}$ need to create a "culture of commitment” by letting their values, behavior, and commitment become a model for other employees. Christian values, which flourish in the actions and the general practice of everyone who serves, from the leaders to the health care workers, must be apparent in the hospital. To create a "culture of commitment", the

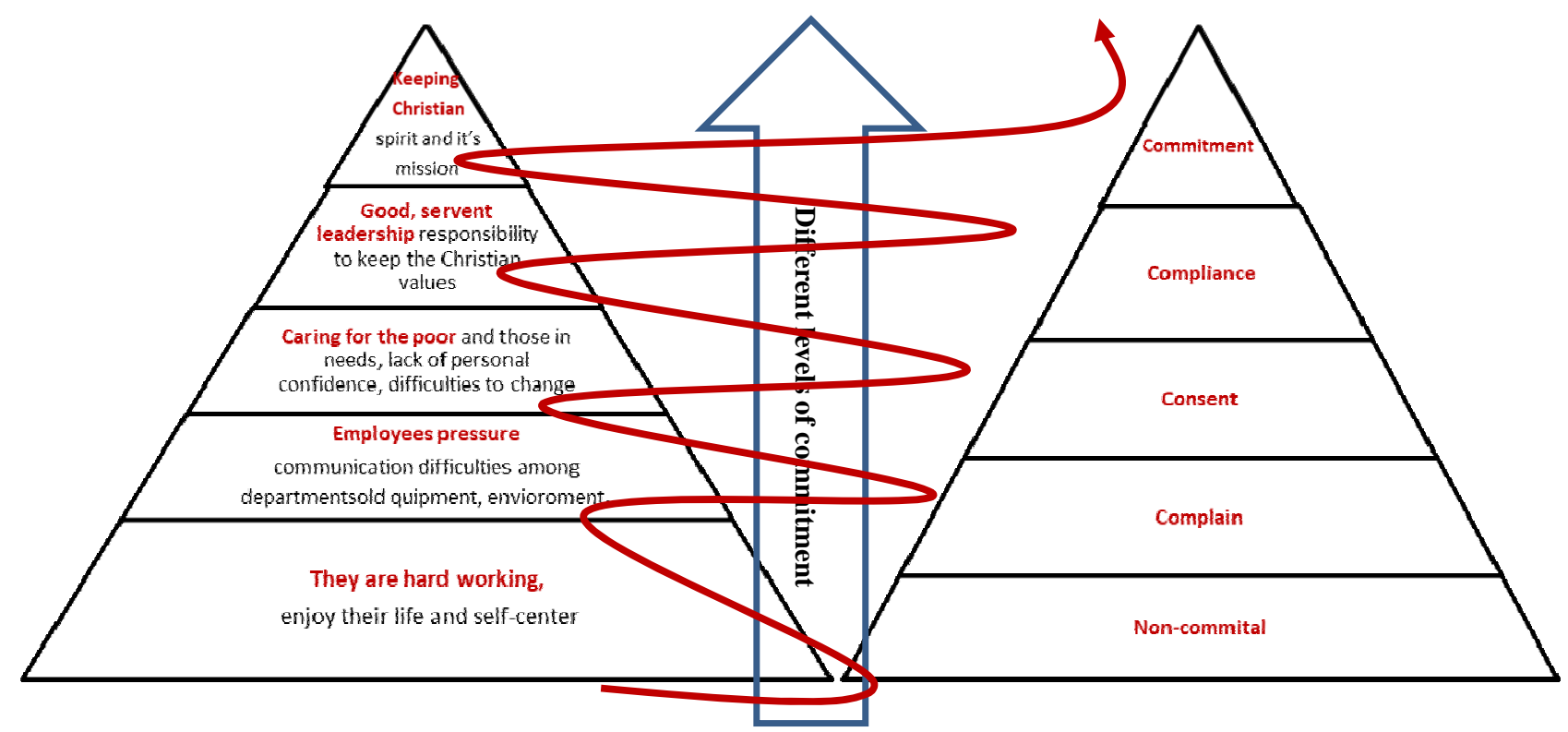

Fig. 2 Pyramid of the needs of employees of the hospital and the "Hierarchy of Commitment" [9]. 
CTH leaders need to create the direction and objectives of the organization. And, to be truly useful, the direction and goals must be inspirational-almost larger than life. It is also part of the Christian spirit of self-sacrifice for a higher value, sacrifice even of one's own life. For this to occur, CTH demands a deeper understanding of organizational commitment theory through different level of commitment (Fig. 2).

In a general sense, we may describe organizational commitment (OC) as an employee's sense of attachment and loyalty to the work organization with which he or she is associated. It is defined in terms of an employee's attitudes and intentions [11]. Employees are considered committed to the hospital when their goals correspond to those of the organization when they are willing to apply themselves unstintingly for the sake of the organization and when they yearn to remain their connection with the organization.

According to Meyer and Allen, OC is comprised of two related concepts-attitude (mindset) and behavior. Attitudinal commitment relates to the process by which employees come to think about their relationship with the organization. It concerns the extent to which employees' values and goals are similar to those of the organization. On the other hand, behavioral commitment transmits to actual practice, by which employees become locked into an organization and how they deal with it. The critical concern is not whether commitment reflects attitudes or behavior, but that organizational commitment involves the interplay of the two [12].

In that sense, the management of the CTH should no longer be a matter of responding to persons on the basis of their economic needs, but rather on the basis of their psychological needs. In that way, in becoming an indispensable servant of employees in their search for "self-fulfillment", the manager becomes their master of motivation [13].

What then should be the proper Christian viewpoint of motivation? We hold that a genuinely Christian standpoint on motivation involves a model change from the model of thought that persons or an institution presently use. The Catholic approach bases itself on two essential traits: service and suffering. Both ought to serve as catalysts for motivation.

In some ways, Maslow's theory can be relevant to Christian missions (non-profit businesses/institutions). When working with employees, it is useful to understand particular spiritual ideas (e.g., salvation) are at the high end of Maslow's hierarchy [14]. Thus, persons with unfulfilled lower level needs must have those needs satisfied before they can concern themselves with more significant needs.

Authentic servant leadership always puts the needs of others above its own needs, including the need to be all that God wills us to be. By merely helping others influence their potential, will we grasp our own potential [15]? However, in the future, together with its leaders, PCD needs to develop clear methods that measure the affective commitment of administrators and employees at large, as well as the values which the hospital has accepted and stood for over the years. It is essential to reflect on the dimensions of engagement: by the desire to maintain a sense of membership and belonging to the hospital, to truly believe in and accept its principles and goals, and a readiness toward exert effort values and goals, and a willingness to exert effort on behalf of the organization. This helps to keep employees in the process of self-reflection, so that they may be more attached to the workplace, making it a home with high values, devoted to the service of society, a place in which continuous growth toward becoming a better person can flourish.

\section{Conclusions}

The author observes in this research that, in keeping with the perspective of pastoral care in the hospital, the employees and leaders need to be continually nourished and supported to succeed at the highest level of their "commitment". However, Maslow's Hierarchy of Needs theory has enabled us to study the present 
situation, and concluded that employees of CTH face a variety of difficulties in their efforts to fulfill the vision and mission of the hospital. A process of self-transcendence continues to require time, guidance, and willingness on the part of the employees here. This study recognizes the strengths of employees uniquely as they face a barrage of daily threats and pressures that originate in governmental requests in conflict with Christian values, and a variety of complexities evident in the overall environment of the medical field.

In general, this study found: (1) the findings here may be limited to only this particular private Catholic hospital, and may not apply to all Catholic hospitals in Taiwan, and (2) the results may not apply to government hospitals on this beautiful island. Finally, to improve the validity of the findings of this study, (1) more investigations should follow in other similar private Catholic hospitals; and (2) research should use instruments different from Maslow's Hierarchy Need theory to measure the constructs of job satisfaction and commitment to the organization.

\section{References}

[1] Maslow, A. 2013. A Theory of Human Motivation. Wilder Publications.

[2] Motivating Employees Inc.com. https://www.inc.com/guides/hr/20776.html.

[3] Health Care Resources. http://education.healthcaresource.com/3-ways-to-increase -healthcare-employee-satisfaction/.

[4] Shalley, C. 1995. "Effects of Coaction, Expected Evaluation, and Goal Setting on Creativity and Productivity.” Academy of Management Journal 38 (2):
483-503.

[5] Pahl, N., and Richter, A. 2007. Swot Analysis-Idea, Methodology, and a Practical Approach. Norderstedt Germany.

[6] "Motivation from a Christian Perspective-Semantic Scholar."

https://pdfs.semanticscholar.org/cfdd/7f77b25a93e256a3 d2b6e36955e8b2a1aa54.pdf.

[7] "Motivation from a Christian Perspective-Semantic Scholar."

https://pdfs.semanticscholar.org/cfdd/7f77b25a93e256a3 d2b6e36955e8b2a1aa54.pdf.

[8] "Motivation from a Christian Perspective-Semantic Scholar."

https://pdfs.semanticscholar.org/cfdd/7f77b25a93e256a3 d2b6e36955e8b2a1aa54.pdf.

[9] Maslow, A. H., Deborah, C. S., and Heil, G. 1998. Maslow on Management. New York: John Wiley.

[10] Jim, L. "Commitment vs. Compliance: How to Get Your Team to 'I Want to Do It!"” https://www.graystoneadvisors.com/commitment-vs-com pliance/.

[11] SAGE Reference: Organizational Commitment Theory. https://sk.sagepub.com/reference/encyclopedia-of-manag ement-theory/i5642.xml.

[12] Mowday, R. T., Porter, L. M., and Steers, R. M. 1982. Employee Organization Linkages: The Psychology of Commitment, Absenteeism, and Turnover. New York: Academic Press.

[13] Hall, D. T., and Nongaim, K. E. 1968. "An Examination of Maslow's Need Hierarchy in an Organizational Setting.” Organizational Behavior and Human Performance.

[14] Porter, B. "Motivation from a Christian Perspective." Hope College Steve VanderVeen, Calvin College. https://pdfs.semanticscholar.org/cfdd/7f77b25a93e256a3 d2b6e36955e8b2a1aa54.pdf.

[15] Lee, H. 1990. The Fabric of This World: Inquiries into Calling, Career Choice, and the Design of Human Work. Grand Rapids, MI: Eerdmans. 